\title{
Effect of Cholecystectomy on Serum Lipids and Blood Glucose (Hospital Based Observational Prospective Study)
}

\author{
Karki OB, Timilsina BD
}

Department of Surgery, Manipal Teaching Hospital, Pokhara, Nepal

Received: January 15, 2021

Accepted: April 25, 2021

Published: April 30, 2021

Cite this paper:

Karki OB, Timilsina BD. Effect of Cholecystectomy on Serum Lipids and Blood Glucose (Hospital Based Observational Prospective Study). Nepal Journal of Medical Sciences 2021;6(1):8-13. http://dx.doi.org/10.3126/ njms.v6i1.36725

\begin{abstract}
Introduction: Association between cholelithiasis and dyslipidemia has been shown in many studies. Recent studies have shown improvement in lipid profile following cholecystectomy. This study aimed to determine the changes in lipid profile and blood glucose level after cholecystectomy.

Methods: Seventy-three patients of cholelithiasis were studied prospectively. Total cholesterol (TC), triglycerides (TG), high-density lipoprotein cholesterol (HDL-c), low-density lipoprotein cholesterol (LDL-c), atherogenic index (AI) and fasting blood sugar (FBS) levels were estimated pre-operatively. Further, the same parameters were studied after cholecystectomy after one week and one-month intervals. None of the patients received any lipid-lowering drug or dietary restriction. Results were analysed and compared.
\end{abstract}

Results: Of the 73 patients with cholelithiasis, $66 \%$ were female and $34 \%$ male. The mean age of patients was $40.53 \pm 13.16$ years. $56 \%$ of patients with cholelithiasis had a deranged lipid profile. TC was significantly decreased at one week $(p=0.002)$ and one month $(p=0.00)$ interval after cholecystectomy while TG levels also decreased significantly at one month postoperative $(\mathrm{p}=0.001)$. There were no significant differences in LDL-c however improvement was seen on HDL-c. Blood glucose level also increased significantly $(p=0.028)$ after one month of cholecystectomy.

Conclusion: Cholelithiasis is associated with an abnormal lipid profile. Cholecystectomy leads to a significant decrease in some of the parameters of lipid profile and the atherogenic index. The presence of gall stones thus should be perceived in the context of metabolic syndrome, which may be investigated and treated.

Keywords: Atherogenic Index; Cholelithiasis; Cholecystectomy; Dyslipidemia

Correspondence to: Dr Bishwo Deep Timilsina Department of Surgery

Manipal Teaching Hospital, Pokhara, Nepal

Email: deepbishow@hotmail.com

\section{INTRODUCTION}

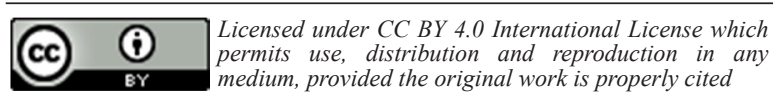


Gallstone disease is a common biliary pathology being prevalent in about 10-15\% of adults in developing countries. ${ }^{1,2}$ Types of gallstone include cholesterol gallstones, pigment and mixed gallstones. However, all stones even pure cholesterol stones also contain small amounts of bilirubin. ${ }^{3}$ Females carry a higher incidence by two to three folds because of sex steroids, use of oral contraceptives and pregnancy changes. ${ }^{4}$ Gallstone diseases result from impaired metabolism of cholesterol, bilirubin and bile acids., ${ }^{2,4}$ This disorder is typically caused by the decrease of bile acids in the bile. ${ }^{3,4}$ Factors including nucleation of cholesterol crystals with mucin and hypomotility of gallbladder also play an equally important role. ${ }^{5}$

About half of the patient with gallstones have an abnormal lipid profile. ${ }^{1,6}$ Gall stone association has been most consistently found with high levels of triglycerides (TG) and low high-density lipoprotein(HDL) whereas, it is inconsistent with low-density lipoprotein( LDL) and total cholesterol(TC) levels., ${ }^{7,8}$

Symptomatic cholelithiasis is usually treated with cholecystectomy. Studies have shown improvement in the lipid profile following cholecystectomy. ${ }^{1,4,5}$ Though lipid and bile acids metabolisms are functionally correlated, how cholecystectomy affects lipid profile is not well-comprehended. ${ }^{9}$ Hypothesis is that post-cholecystectomy there is a reduction in the bile acid pool size and an increase in the frequency of entero-hepatic circulation. ${ }^{10}$

The study aimed to evaluate the lipid profile of patientswithgallstonepreandpost-operatively, establish the effect of cholecystectomy on lipid profile and blood sugar and also evaluating the correlation between the type of stones and serum lipid profile.

\section{METHODS}

This prospective observational study was conducted in the Department of General Surgery in Manipal Teaching Hospital, Pokhara, Nepal from January 2018 to January 2020. Seventy-three patients of cholelithiasis diagnosed by ultrasound or Computed tomography (CT scan) of abdomen planned for cholecystectomy were studied prospectively. All patients underwent a detailed history and clinical examination. Baseline investigations were obtained preoperatively.

Patients suffering from conditions like diabetes mellitus, renal failure, hypothyroidism, nephritic syndrome, hemoglobinopathies, morbid obesity which are known to alter the lipid levels were excluded from the study. Similarly, patients on lipid-lowering agents, intrahepatic stones, patients with obstructive jaundice, pregnant females were also excluded. The fasting lipid profile (total cholesterol, triglycerides, LDL cholesterol and HDL cholesterol) and fasting blood sugar of all these patients were obtained preoperatively on the morning of surgery. All patients underwent laparoscopic or open cholecystectomy under general anaesthesia. After cholecystectomy, the specimen was sent for histopathological examination and gallbladder stones for analysis. Usual postoperative care was given to all patients. Fasting blood sugar and lipid profile were again obtained on second-week post-surgery when patients were followed up for suture removal. Patients were followed after one month with fasting blood sugar and fasting lipid profile and compared with the initial profile. Gallstones were analyzed for the chemical nature of the stones and correlation was done between the type of the stone and preoperative serum lipid levels. Atherogenic index (AI) was calculated by the following equation

$\mathrm{AI}=$ Total serum cholesterol/HDL cholesterol. ${ }^{11}$ None of the patients was put on any lipidlowering drug or any dietary restriction.

The study was approved by the Institutional ethics committee of the hospital. Written and informed consent was taken from all the patients or his/her guardian. All statistical analyses were performed using Excel spreadsheets and Statistical Package for Social Sciences (SPSS) for Windows (Version 20). Descriptive analysis of all the explanatory and outcome parameters was done using frequency and proportions for categorical variables, whereas in mean and standard deviation for continuous variables. A 95\% confidence 
interval was taken into consideration and $\mathrm{p}<$ 0.05 was regarded as statistically significant

\section{RESULTS}

Of the total 73 patients under study, 48(66\%) were females, 25(34\%) were males. The age of patients ranged from 15 to 74 years. The mean age of patients was $40.53 \pm 13.16$ years. The majority of patients belonged to the middle age group with $47 \%$ of them between $40-60$ yrs followed by $42 \%$ of patients in 20-40 years age group. (Table 1)

Cholesterol was raised in 19\% of patients.

Table 1: Age-group wise distribution of patients

\begin{tabular}{lll}
$\begin{array}{c}\text { Age-group } \\
\text { (years) }\end{array}$ & \multicolumn{1}{c}{$\begin{array}{c}\text { Number of } \\
\text { patients }\end{array}$} & Percentage \\
$0-20$ & 5 & 7 \\
$20-40$ & 31 & 42 \\
$40-60$ & 34 & 47 \\
$60-80$ & 3 & 4 \\
\hline
\end{tabular}

Fifty-six percent patients with gallstone diseases had a deranged lipid profile. TG was raised in $35 \%$ of patients. Increased level of LDL-c was seen in $36 \%$ of patients and HDL-c was low in $26 \%$ of patients.

On comparing the changes in lipid profile parameters in gallstone patients before and after cholecystectomy, there was a significant decrease in the level of total cholesterol after one week and one month $(\mathrm{p}=0.00)$ of cholecystectomy but triglyceride was significantly reduced in patients only after one month of cholecystectomy $(\mathrm{p}=0.001)$. Similarly, there was a rise in the level of HDL one-week post-surgery but a significant rise was observed only one month $(\mathrm{p}=0.00)$ postcholecystectomy. There was no significant decrease in the level of LDL-c even after one month of cholecystectomy in gallstone disease patients. There was a significant rise in FBS level $(p=0.028)$ after one month of cholecystectomy in gallstone disease patients. (Table 2).

Table 2: Lipid profile parameters and fasting blood glucose in the patients preoperatively, one week post operatively and one month postoperatively

\begin{tabular}{|c|c|c|c|c|c|}
\hline Parameters & $\begin{array}{l}\text { Pre- operative } \\
\text { Mean (SD) }\end{array}$ & $\begin{array}{l}1 \text { week postop } \\
\text { Mean (SD) }\end{array}$ & $\mathrm{p}$ value & $\begin{array}{c}1 \text { month postop } \\
\text { Mean (SD) }\end{array}$ & $\mathrm{p}$ value \\
\hline FBS $(\mathrm{mg} / \mathrm{dl})$ & $91.36(10.17)$ & $89.30(11.03)$ & 0.148 & $94.77(12.28)$ & 0.028 \\
\hline $\mathrm{TC}(\mathrm{mg} / \mathrm{dl})$ & $168.1(33.15)$ & $155.42(39.18)$ & 0.002 & $144.55(37.13)$ & 0.00 \\
\hline $\mathrm{TG}(\mathrm{mg} / \mathrm{dl})$ & $138.22(56.60)$ & $134.66(73.14)$ & 0.595 & $120.78(35.05)$ & 0.001 \\
\hline HDL-c (mg/dl) & $44.47(9.04)$ & $46.62(10.98)$ & 0.116 & 49.97(9.00) & 0.00 \\
\hline L DL-c (mg/dl) & $99.04(27.35)$ & $100.03(22.90)$ & 0.748 & $95.70(19.70)$ & 0.294 \\
\hline AI (TC/HDL-c) & 3.78 & 3.33 & & 2.89 & \\
\hline
\end{tabular}

FBS=Fasting Blood Sugar, TC=Total cholesterol, TG=Triglycerides, HDL-c=High density lipoprotein cholesterol, LDL-c=Low density lipoprotein cholesterol, $\mathrm{AI}=\mathrm{Atherogenic}$ index

There was a decrease in the value of the atherogenic index at one week and one month after cholecystectomy compared to the value before cholecystectomy. It was because of a decrease in total cholesterol with a rise in HDL cholesterol.

In our study, mixed type of gallstones was most common (55\%) followed by cholesterol stones (45\%). Only a few patients (5\%) had pigmented stones. (Table 3 )
Table 3: Types of gallbladder stones

$\begin{array}{lll}\text { Type of stone } & \text { Number } & \text { Percentage } \\ \text { Cholesterol stone } & 29 & 40 \\ \text { gment stone } & 4 & 5 \\ \text { ixed stone } & 40 & 55\end{array}$




\section{DISCUSSION}

In our study, the prevalence of cholelithiasis was higher in females than in males. This is similar to other studies. ${ }^{2,8}$ Higher incidence in females could be due to estrogen in females that increases biliary cholesterol secretion causing cholesterol supersaturation of bile. Oral contraceptives increase cholesterol secretion and decrease bile acids, resulting in the supersaturation of bile and increasing lithogenicity. ${ }^{4}$ However, one study from Chine showed a higher prevalence in men than in women..$^{12}$ Maximum incidence (47\%) of gallstone diseases was noted in the 40-60 years age group followed up by $42 \%$ in 20 40 years. Jindal et al. found a high incidence of gallstone diseases in the middle age group (41-50 years). ${ }^{11}$ Menezes et al. had maximum incidence of gallstone disease (26\%) in the third decade. ${ }^{13}$

Most of the patients with gallstones are not evaluated for any metabolic disorder. Many studies have shown that untreated gallstone disease patients present with hypercholesterolemia. In this study, dyslipidemia was present in half of the patients which is in accordance with the results of other studies. ${ }^{11,14}$

Serum concentrations of TC were significantly reduced in patients after cholecystectomy at the one-week interval and one month thereafter. Similarly, TG and HDL-c levels after one month of surgery were significantly decreased. Similar findings have been noticed in other studies. ${ }^{4,5,15}$ But Malik et al. reported no change in HDL-C levels after 6 months of surgery. ${ }^{5}$ Following cholecystectomy, there is a significant increase in bile acids and phospholipids secretion leading to improvement in bile composition and a reduction in bile acids pool occurring due to altered enterohepatic circulation, leading to a reduction in serum cholesterol. ${ }^{1,5,11}$ However, a study by Chavez et al. showed cholecystectomy increased high cholesterol levels. ${ }^{16}$ Studies from China showed cholecystectomized subjects had a higher prevalence of metabolic syndrome and its compound of features than subjects with gallstones or normal gallbladder. ${ }^{17}$ High blood glucose seen in cholecystectomized patients may be due to the return of the patients to the normal lifestyle and administration of a large amount of fatty diet or high carbohydrates diet or as a part of metabolic syndrome. This significant increase in blood glucose after cholecystectomy is in accordance with study by Alkataan et al. who also found an increasing trend in fasting blood glucose levels post cholecystectomy. ${ }^{15}$

In our study, mixed type of gallstones was most common (55\%) followed by cholesterol stones $(45 \%)$. Only a few patients (5\%) had pigmented stones. This result is similar to a study by Pradhan SB et al. who reported $78.75 \%$ of gallstones as mixed stones followed by $12.5 \%$ cholesterol stones and $1.25 \%$ pigment stones. ${ }^{18}$

\section{CONCLUSION}

The present study demonstrates a deranged lipid profile in gallstone disease patients. Cholecystectomy does have a favourable effect on the lipid profile of patients, especially triglyceride and cholesterol level. Still the changes in the profile of some serum lipids following cholecystectomy remain an issue of controversy. We recommend longterm follow-up of these patients with the multicentric study.

\section{CONFLICT OF INTEREST}

None

\section{SOURCES OF FUNDING}

None

\section{REFERENCES}

1. Khuroo MS, Mahajan R, Zargar SA, Javid G, and Sapru S. Prevalence of biliary tract disease in India: A sonographic study in adult population in Kashmir. Gut. 1989;30(2):201-5. https:// doi.org/10.1136/gut.30.2.201

2. Unisa S, Jagannath P, Dhir V, Khandelwal C, Sarangi L, Roy TK. Population-based study to estimate prevalence and determine 
risk factors of gallbladder diseases in the rural Gangetic basin of North India. HPB. 2011;13(2):117-25. https:// doi.org/10.1111/j.1477-2574.2010.00255.x

3. Karlatti SS, Kumar GR. Incidence of Various Types of Gallstones in Patients of Cholelithiasis in Belgavi. Int $\mathrm{J} \mathrm{Sci}$ Stud. 2016;4(7):21-3. https://10.17354/ ijss/2016/518

4. Gill GS, Gupta K. Pre- and post-operative comparative analysis of serum lipid profile in patients with cholelithiasis. Int $J \mathrm{Appl}$ Basic Med Res. 2017;7(3):186-8. https:// doi.org/10.4103/2229-516X.212968

5. Malik AA, Wani ML, Tak SI, Irshad I, UlHassan N. Association of dyslipidaemia with cholelithiasis and effect of cholecystectomy on the same. Int J Surg. 2011;9(8):641-2. https://doi.org/10.1016/j. ijsu.2011.08.003

6. Rao PJ, Jarari A, El-Awami H, Patil TN, ElSaiety SO. Lipid profile in bile and serum of cholelithiasis patients-A comparative study. Journal of basic medical and Allied sciences. 2012;1(2):27-39.Available from: https://tinyurl.com/w3n9nuy3

7. Attili AF, Capocaccia R, Carulli N, Festi D, Roda E, Barbara L et al. Factors associated with gallstone disease in the MICOL experience. Multicenter Italian Study on Epidemiology of Cholelithiasis. Hepatology. 1997;26(4):809-18. https:// doi.org/10.1002/hep.510260401

8. Batajoo H, Hazra NK. Analysis of serum lipid profile in cholelithiasis patients. $J$ Nepal Health Res Counc. 2013;11(23):535. Available from: https://pubmed.ncbi. nlm.nih.gov/23787527/ [Accessed 28th October 2020]

9. Haq AM, Giasuddin AS, Jhuma KA, Choudhury MA. Effect of cholecystectomy on lipid profile in Bangladeshi patients with cholelithiasis. $J$ Metabolic Synd. 2015;5(1):192. https://doi. org/10.4172/2167-0943.1000192

10. Ahi KS, Singh RP, Kaur H, Moudgil A. Serum lipid profile in pre and post cholecystectomy patients. Int $J$ Anat Radiol Surg. 2017;6(2):1-6. Available from: http://www.ijars.net/article fulltext. asp? issn $=0973-709 x$ \&year $=2017 \&$ month $=$ April\&volume $=6$ \&issue $=2$ \&page $=$ SO01$\underline{\text { SO06\&id }=2267 \text { [Accessed 26th March }}$ 2021]

11. Jindal N, Singh G, Ali I, Sali G, Reddy R. Effect of cholelithiasis and cholecystectomy on serum lipids and blood glucose parameters. Arch of Int Surg. 2013;3(2):97-101. https://doi. org/10.4103/2278-9596.122926

12. Chen LY, Qiao QH, Zhang SC, Chen $\mathrm{YH}$, Chao GQ, Fang LZ. Metabolic syndrome and gallstone disease. World $J$ Gastroenterol. 2012;18(31):4215-20. https://doi.org/10.3748/wjg.v18.i31.4215

13. Menezes JVF, Katamreddy RR. The effect of cholecystectomy on the lipid profile of patients with gallstone disease: a prospective study. Int Surg J. 2019;6(11):4112-6. https://doi. org/10.18203/2349-2902.isj20195133

14. Méndez-Sánchez N, Chavez-Tapia NC, Motola-Kuba D, Sanchez-Lara K, Ponciano-Rodríguez G, Baptista $\mathrm{H}$, Ramos $\mathrm{MH}$, Uribe M. Metabolic syndrome as a risk factor for gallstone disease. World J Gastroenterol. 2005;11(11):1653-7. https://doi.org/10.3748/wig.v11.i11.1653

15. AL-Kataan MA, Bashi AY, Al-Khyatt MK. Some serum lipid profile and glucose levels pre- and post-cholecystectomy. $J$ Bahrain Med Soc. 2010;22(1):1822. Available from: http://www.jbms. org/contentmanager/22021171478.pdf [Accessed 27th March 2021]

16. Chavez-Tapia NC, Mac Kinney-Novelo I, Sifuentes-Rentería SE, Torres-Zavala M, Castro-Gastelum G, Sánchez-Lara $\mathrm{K}$ et al. Association between cholecystectomy for gallstone disease and risk factors for cardiovascular disease. Ann Hepatol. 2012;11(1):85-9. https://doi.org/10.1016/ S1665-2681(19)31490-5

17. Shen $\mathrm{C}, \mathrm{Wu} \mathrm{X}, \mathrm{Xu} \mathrm{C}, \mathrm{Yu} \mathrm{C}$, Chen $\mathrm{P}$, Li Y. Association of cholecystectomy with metabolic syndrome in a Chinese population. PLoS One. 2014;9(2):e88189. https://doi.org/10.1371/journal. 
pone. 0088189

18. Pradhan SB, JoshiMR, Vaidya A.prevalence of different types of gall stone in the patients with cholelithiasis at Kathmandu Medical College, Nepal. Kathmandu Univ Med J (KUMJ). 2009;7(27):268-71. https://doi.org/10.3126/kumj.v7i3.2736 